\title{
Telejornalismo e juventude em tempos de pandemia: comunicação de interesse público
}

\author{
Taianne de Lima Gomes ${ }^{1}$ \\ Valquiria Aparecida Passos Kneipp ${ }^{2}$
}

\begin{abstract}
Resumo
Com a pandemia, em 2020, de acordo com pesquisas, o jovem passou a assistir telejornal, formato televisivo que estava em baixa nessa camada da população. $O$ artigo se faz necessário para registrar este novo cenário midiático, identificar novas práticas sociais e contribuir para a reflexão do telejornalismo. Trata-se de estudo de caso exploratório. Buscou-se responder como a pandemia levou a juventude de volta ao telejornal? A base conceitual e teórica calcou-se nos estudos sobre a história da mídia televisiva e do telejornalismo. Considerou-se que a juventude voltou ao noticiário de TV visando obter informação verdadeira, em meio às fakes news.
\end{abstract}

Palavras-chave:

Telejornalismo. Juventude. COVID-19.

\begin{abstract}
In the pandemic, in 2020, according to research, youth started to watch television news, a television format that was low in this section of the population. This article is necessary to register this new media scenario, identify new social practices and contribute to the reflection of telejournalism. This is an exploratory case study. Did you try to answer how the pandemic took youth back to the news? The conceptual and theoretical basis was based on studies on the history of television media and television news. It was considered that the youth returned to the television news in order to obtain true information, amid the fake news.
\end{abstract}

\section{Keywords}

Telejournalism. Youth. COVID-19.

\footnotetext{
1 Doutoranda do Programa de Pós-graduação em Estudos da Mídia, na Universidade Federal do Rio Grande do Norte (UFRN). taiannegomes@hotmail.com

2 Pós-doutoranda em Comunicação na Universidade Estadual Paulista Júlio de Mesquita Filho (Unesp). Doutora em Ciências da Comunicação pela Universidade de São Paulo. Professora do Programa de Pós-graduação em Estudos da Mídia, na Universidade Federal do Rio Grande do Norte (UFRN). valquiriakneipp@yahoo.com.br
} 


\section{Juventude e o consumo de televisão}

No ano de 2020 a pandemia do novo coronavírus acometeu o mundo. Novas normas de isolamento e comportamento social foram, de uma hora para outra, impostas a todos. Neste novo contexto, de acordo com as pesquisas, o jovem passou a assistir um formato televisivo que estava em baixa para esta camada da população - o telejornalismo.

Anteriormente se tem o registro do afastamento do jovem dos noticiários televisivos tendo em vista a convergência e a midiatização da sociedade. Dessa forma, esta pesquisa se faz necessária para registrar e buscar identificar este cenário midiático, em função do contexto pandêmico, e contribuir, assim, para a reflexão acerca do telejornalismo.

Por meio de estudo exploratório, este artigo tem como objetivo investigar o cenário de mudança de comportamento da juventude e analisar a relação com o telejornalismo. Utilizando pesquisa bibliográfica, apresenta os passos iniciais para a construção de um estado da arte dos estudos que envolvem os objetos de análise deste trabalho e busca responder: a pandemia levou o jovem de volta ao telejornal? Partiu-se da hipótese que, devido à pandemia, o jovem teve a necessidade de se informar por meio de fontes fidedignas, como o telejornalismo.

Cabe destacar que o termo juventude, referendado pela Constituição Brasileira, no artigo 227, e também pelo Estatuto da Juventude, se refere a jovens com idade entre 15 e 29 anos. Desta forma, a pesquisa considera esta faixa etária para identificar o jovem brasileiro que se investiga. (BRASIL, 1988).

De acordo com o Censo de 2010, há no Brasil 51,3\% jovens de 15 a 29 anos de idade, o que equivale a cerca de $1 / 4$ da população do país. A juventude brasileira representa uma parcela significativa da população e tem sido objeto empírico de diversas pesquisas relativas ao consumo midiático, entre outros assuntos. (IBGE, 2010).

Em 2008 o IBASE/PÓLIS mostrou que os meios de informação mais utilizados pelos jovens entre 18 e 29 anos são a televisão com 94,3\%; o rádio comercial com 38,6\%; jornal/revistas impressos com 34\%; a internet com 33,2\%; rádio comunitária 4,5\%; e 0,6\% nenhum destes (BRASIL, 2008).

Em 2013, a Pesquisa Nacional sobre Perfil e Opinião dos Jovens Brasileiros realizada Secretaria Nacional de Juventude, entre os oito tópicos do levantamento feito (perfil e condição juvenil; tecnologia de informação e comunicação; a escola e a formação profissional; o mundo do trabalho; violência contra a juventude negra; temas da juventude e percepções do país; vida política; e políticas para a juventude), a parte que trata da tecnologia da informação e comunicação revelou que a tendência de velocidade com que as novas gerações absorvem o uso de novas tecnologias foi confirmada.

De acordo com a pesquisa, em relação aos meios pelos quais o jovem costuma se informar sobre o que acontece no Brasil e no mundo, $83 \%$ deles mencionam a televisão 


\section{VOZES $_{\& \text { DIÁLORO }}^{\downarrow}$}

Itajaí, V. 19, n.02, jul-dez 2020

aberta, $56 \%$ a internet, $23 \%$ os jornais impressos, $21 \%$ as rádios comerciais e $17 \%$ a TV paga.

Outro ponto importante sobre tecnologia da informação e comunicação é que oito em cada dez entrevistados (80\%) usam computador e/ou internet, sendo a grande maioria (75\%) usuária de ambos. A pesquisa apontou, ainda, que o acesso à internet acontece pelo computador ou celular. Quanto às finalidades de uso da internet, as principais citadas pelos jovens são: sites de relacionamento (56\%); buscar notícias sobre a atualidade (43\%); pesquisas/mecanismos de busca (31\%); baixar músicas e vídeos (23\%); e enviar/receber emails (23\%) (BRASIL, 2013).

Os dados das pesquisas referenciadas revelam que a televisão ocupava um lugar de destaque na preferência dos jovens para se informar e que, ao longo do tempo, a TV foi perdendo este espaço, saindo de 94,3\% para 83\%. Já a Internet fez o caminho inverso, em termos de cobertura e uso por parte dos jovens. As preferências e usos midiáticos revelam um estágio avançado no processo de midiatização, caracterizada por Hjarvard (2014, p. 25), como "as problemáticas concomitâncias ou consequências do desenvolvimento dos modernos meios de comunicação de massa”, que se torna latente como resultado da cultura da convergência e da conexão propostas por Jenkins (2009).

\section{Televisão tradicional X TV interativa}

Neste estudo se considera televisão tradicional aquela de distribuição gratuita de um para muitos, em formato digital, com sinal aberto, que compõe o espectro brasileiro, com a proeminência de cinco redes de televisão (Globo, SBT, Record, Band e TV Cultura) com cobertura nacional, que são responsáveis pelos principais telejornais, que distribuem informação para a população brasileira.

Já a TV Interativa (TVi) está intrinsecamente relacionada a convergência entre TV e outras mídias ou tecnologias, como computador, tablet e celular. Segundo Médola e Teixeira (2008, p. 3), "não se restringe à digitalização, ela se constitui de fatores humanos intrínsecos à recepção, na percepção e no relacionamento do indivíduo com o meio”.

As diferenças básicas entre televisão tradicional e televisão interativa podem ser observadas abaixo, de acordo com Adams et al (2001, apud MÉDOLA; TEIXEIRA, 2008): 


\section{VOZES $_{\text {\&IÁLORO }}^{\mid}$}

Itajaí, V. 19, n.02, jul-dez 2020

Quadro 1 - Diferenças entre TV tradicional e TV interativa

\begin{tabular}{|c|c|}
\hline TV tradicional & TV interativa \\
\hline Expectador passivo & Usuário ativo \\
\hline $\begin{array}{c}\text { O conteúdo é empurrado até a } \\
\text { audiência }\end{array}$ & O conteúdo é puxado pela audiência \\
\hline $\begin{array}{c}\text { Modelo de programação em função dos } \\
\text { canais de transmissão }\end{array}$ & $\begin{array}{c}\text { Modelo de programação com conteúdo } \\
\text { disponível em banco de dados }\end{array}$ \\
\hline Programação linear & Programação participativa \\
\hline Dispositivo Central & Ubiqüidade \\
\hline Uso principal para o entretenimento & $\begin{array}{c}\text { Uso estendido a compras, } \\
\text { comunicação, integração social e } \\
\text { educação }\end{array}$ \\
\hline $\begin{array}{c}\text { Plataforma de comunicação de uma só } \\
\text { direção }\end{array}$ & $\begin{array}{c}\text { Plataforma de comunicação } \\
\text { bidirecional }\end{array}$ \\
\hline $\begin{array}{c}\text { Os emissores conhecem bem o seu } \\
\text { papel }\end{array}$ & $\begin{array}{l}\text { O papel do emissor passa a ser flexível e } \\
\text { requer maior integração }\end{array}$ \\
\hline
\end{tabular}

Fonte: Elaborado pelas autoras (2020).

No entanto, cabe ressaltar que a televisão tradicional está em baixa, principalmente, entre o público jovem, é o que apontam pesquisas no mundo todo, conforme alguns exemplos brasileiros apresentados no tópico anterior.

De acordo com a última edição do General Media Framework na Espanha (AIMC, 2018 apud VALERO-PASTOR, 2019), a audiência caiu em 2017 em 85,2\%, o pior valor em 35 anos. A queda é ainda mais significante em grupos entre 14 e 34 anos. Já nos Estados Unidos, de acordo com o estudo do Pew Research Center (SHEARER; GOTT, 2017 apud VALERO-PASTOR, 2019) sobre consumo de mídia, a audiência ao telejornalismo cai em quase todas as faixas etárias, enquanto o acesso às redes sociais cresce quando o assunto é notícia: 52\% dos estadunidenses entre 18 e 29 anos são informados on-line, em comparação com 23\% que ainda utilizam a televisão (VALERO-PASTOR, 2019). Sobre esse aspecto Valero-Pastor (2019) afirma que a Internet não para de crescer desde a sua introdução e é, desde 2014, o meio favorito para a geração milenar e geração Z3 .

Há dois motivos que explicam a queda no consumo de notícias pela televisão entre os jovens. "Esse setor demográfico prefere outros tipos de plataformas sociais e móveis que oferecem uma maior velocidade e interação.” (YUSTE, 2015, apud VALERO-PASTOR, 2019, p. 173, tradução nossa). Além disso, o autor acredita que os jovens não se interessam

\footnotetext{
${ }^{3}$ Geração Z (também conhecida por Gen Z, iGeneration, Plurais ou Centennial) é a definição dada à geração de pessoas que nasceu entre o começo dos anos 90 e o fim da primeira década do século XXI.
} 


\section{VOZES $_{\text {\&IÁLORO }}^{\mid}$}

Itajaí, V. 19, n.02, jul-dez 2020

pelo conteúdo oferecido na mídia tradicional, porque não contemplam suas necessidades e interesses (YUSTE, 2015, apudVALERO-PASTOR, 2019).

Alguns estudiosos são mais específicos e acreditam que o declínio na audiência de TV entre os jovens é mais expressivo para programas de notícias. "Embora muitas pessoas com mais de 55 anos consumam televisão regularmente, as notícias não são mais interessantes para a maioria dos menores de 30 anos, que praticamente abandonaram os noticiários.” (NEWMAN et al, 2018 apud GARCÍA-AVILÉS, 2020, p. 144).

Nesse aspecto, Drok et al (2018 apud GARCÍA-AVILÉS, 2020) também acredita que os jovens não estão interessados em notícias, “é difícil conciliar esse segmento etário com noticiários, porque o formato requer atenção mínima que esses jovens multitarefas não estão dispostos a dar.” (DROK et al, 2018 apud GARCÍA-AVILÉS, 2020, p. 144).

Dessa forma, entre os desafios pela frente da televisão tradicional está a necessidade de utilização de novas plataformas de mídia, bem como a utilização de narrativas transmídia. "É assim necessário experimentar novas linguagens, estabelecer uma maior cumplicidade entre a mídia e o público, incorporar jornalistas e apresentadores com quem os jovens se identifiquem, aumentando assim a interação com os usuários” (KALOGEROPOULOS et al, 2016 apud GARCÍA-AVILÉS, 2020, p. 145).

Nesse sentido, García-Avilés (2020) cita alguns exemplos de inovação na narrativa audiovisual que buscam captar a audiência jovem, como apontado no quadro abaixo:

Quadro 2 - Programas inovadores na narrativa audiovisual

\begin{tabular}{|c|c|c|}
\hline Programa & Emissora & Descrição \\
\hline Stay Tuned & NBC News (EUA) & $\begin{array}{r}\text { Noticiário com dois minutos de duração } \\
\text { apresentado por três jornalistas com menos } \\
\text { de } 30 \text { anos de idade no Snapchat, } \\
\text { Instagram e Youtube. }\end{array}$ \\
\hline Hochkant & ARD & $\begin{array}{c}\text { Três jovens apresentadores, que se } \\
\text { denominam snappers, divulgam notícias } \\
\text { por meio de fotos informativas e vídeos com } \\
\text { breves comentários, muitas vezes o material } \\
\text { gerado é oriundo dos próprios seguidores. }\end{array}$ \\
\hline ZIB100 & $\begin{array}{c}\text { ORF } \\
\text { Oferece pílulas de notícias de dois minutos } \\
\text { em formato de vídeo e legendado no } \\
\text { WhatsApp, Facebook e Twitter. }\end{array}$ \\
\hline Outside Source & $\begin{array}{c}\text { BBC News (Reino } \\
\text { Unido) }\end{array}$ & $\begin{array}{c}\text { Utiliza conteúdo gerado pelo usuário nas } \\
\text { redes sociais de maneira visualmente } \\
\text { atraente. O formato é exibido nas redes de } \\
\text { TV BBC World News e BBC News. }\end{array}$ \\
\hline
\end{tabular}




\begin{tabular}{|c|c|c|}
\hline NowThisNews & Exibido nos EUA & $\begin{array}{c}\text { Trinta jornalistas geram cerca de } 40 \text { peças } \\
\text { diárias de notícias de última hora, alguns } \\
\text { vídeos narrados por apresentadores jovens, } \\
\text { utilizando linguagem coloquial. O material é } \\
\text { disponibilizado no Facebook, Twitter e } \\
\text { Snapchat. }\end{array}$ \\
\hline $\begin{array}{c}\text { VICE News } \\
\text { Tonight }\end{array}$ & HBO (EUA) & $\begin{array}{c}\text { Sem apresentador, traz um resumo das } \\
\text { notícias do mundo em formato visualmente } \\
\text { atraente com gráficos e músicas. }\end{array}$ \\
\hline
\end{tabular}

Fonte: Elaborado pelas autoras (2020).

De acordo com o García-Avilés (2020, p. 153), “esses formatos não fornecem todas as soluções, mas oferecem oportunidades aos produtores arriscar, experimentar e escapar de sua zona de conforto, principalmente tentando alcançar espectadores com menos de 30 anos”.

Para o autor, o público jovem deve ser levado a sério pelas emissoras de notícias. "Os jovens exigem conteúdo significativo para eles. Além disso, é necessário reduzir as influências políticas e comerciais para garantir independência na cobertura noticiosa”. (GARCÍA-AVILÉS, 2020 p. 154).

Mesmo não sendo possível fazer previsões, segundo García-Avilés (2020), os telejornais permanecerão sendo um formato relevante por muito tempo, no entanto, é possível conviver com propostas distintas: "há muito espaço para um produto diário contextualizado, divertido e visual que ajude entender um volume avassalador de dados e informações”. (GARCÍA-AVILÉS, 2020, p. 154).

Nesse aspecto, a combinação entre televisão, Internet e mídias sociais se apresentam como plataformas ideais para esse novo formato. "O desafio é como torná-lo relevante, útil e satisfazer as necessidades dos usuários, sem comprometer os valores de confiança, transparência e credibilidade em um mundo de mídia cada vez mais personalizada e polarizada”. (GARCÍA-AVILÉS, 2020, p. 154).

\section{Televisão tradicional e o Telejornalismo}

A televisão, de acordo com pesquisas, é a principal mídia do sistema de comunicação de massa brasileiro. Para Mata (2017), a comparação entre os 200 primeiros aparelhos de televisão em 1950 e os 103,3 milhões de TVs nos lares brasileiros, conforme apontados pela Pesquisa Nacional por Amostra de Domicílios 2015, mostra a relevância da televisão na vida dos brasileiros, que, conforme pesquisa da Kantar IBOPE Media, é consumida por $98 \%$ da população do País (MATA, 2017, p. 69). 


\section{VOZES $_{\text {\&IÁLORO }}^{\mid}$}

Itajaí, V. 19, n.02, jul-dez 2020

De acordo com dados da Pesquisa Brasileira de Mídia 2016 - Hábitos de Consumo de Mídia pela População Brasileira (BRASIL, 2016), quase 90\% da população se informa pela TV sobre o que acontece no país. Desse total, 63\% tem a TV como a principal mídia para informação. A internet aparece em segundo lugar como meio preferido de $26 \%$ dos entrevistados e é apontada como uma das duas principais fontes de informação por $49 \%$.

As pesquisas e os estudos, portanto, mostram a centralidade da TV no século XXI e continuam apontando esse crescimento ao longo da década atual. Nesse contexto, Santos (2018) corrobora "julgamos pertinente reafirmar nossa contrariedade a qualquer viés que aponte para o fim da televisão” (SANTOS, 2018, p. 38). O fascínio pela TV permanece e uma das razões pode ser a acessibilidade. "A TV não exige escolaridade e poder aquisitivo, como outros bens de serviços e culturais, é relativamente barata, consumida mais que geladeira, segundo o IBGE.” (BECKER, 2005, p. 21).

No entanto, é importante destacar que já existe uma concorrência com a internet. "Todavia não podemos parar no tempo e no espaço: a reflexão deve ser permanente. A concorrência com a internet e a busca por novos modelos de negócio tencionam a hegemonia do principal meio de comunicação de massa do século XX.” (SANTOS, 2018, p. 37).

Nesse contexto, a convergência de mídias se apresentam como uma alternativa considerando que o cinema não eliminou o teatro, a TV não eliminou o rádio e, por sua vez, a internet não eliminou a TV. Os meios passaram naturalmente a conviver juntos. Cannito (2010, p. 28), por exemplo, entende que as diversas mídias atuam de maneira integrada, não mais de forma isolada:

Estou convencido de que a televisão continuará tendo grande importância e de que entender suas especificidades será um grande diferencial na construção de conteúdos transmidiáticos. A televisão sempre atuará com a programação de massa, feita para o público genérico, e continuará sendo a catalizadora das outras mídias (CANNITO, 2010, p. 72).

França (2009, p. 49) corrobora e afirma que "mais do que nunca os diferentes meios de comunicação constituem uma rede integrada”. Para a autora, o cenário atual "mais reforça que enfraquece os diferentes meios”. A mesma perspectiva é apresentada por García Canclini (2008, p. 33). "As fusões multimídia e as concentrações de empresas na produção de cultura correspondem, no consumo cultural, à integração de rádio, televisão, música, notícias, livros, revistas e Internet”.

O uso casado das mídias é, portanto, uma realidade. "O usuário às vezes acessará a internet, mas continuará usando a televisão para o que ela faz de melhor: exibir bons programas televisivos. E o público continuará sabendo, intuitivamente, qual a diferença entre o conteúdo televisivo e os conteúdos da internet”. (CANNITO, 2010, p. 26). 


\section{VOZES $_{\text {\&IÁLORO }}^{\mid}$}

Itajaí, V. 19, n.02, jul-dez 2020

Os autores citados concordam que as mídias se complementam e podem conviver simultaneamente. Nesse aspecto, Santos (2018) reitera:

O que concluímos, a partir disso, é que não se trata de decretar o fim do broadcasting ou do fluxo televisivo, mas de um novo modelo de consumo que deixa ao telespectador a possibilidade de ter acesso aos conteúdos que mais atendem aos seus interesses no momento em que escolher assisti-lo (SANTOS, 2018, p. 36).

O telejornalismo, nesses 70 anos, tem se consolidado como a maior fonte de informação da população. Para Martins (2017), “a história da televisão brasileira também pode ser contada pelo desenvolvimento e pela importância dada ao seu telejornalismo, considerado como carro-chefe de muitas emissoras" (MARTINS, 2017, p. 41). O noticiário na TV aberta, pela sua tradição, chega a ser quase intocável na grade da programação televisiva, mesmo com índices de audiência menos representativos do que no passado. "Os telejornais, produtos de informação de maior impacto na sociedade contemporânea ‘vendem' credibilidade e atraem investimentos” (BECKER, 2005, p. 48).

Na Pesquisa Brasileira de Mídia 2015, sobre os hábitos de consumo de mídia pela população brasileira, 79\% das pessoas entrevistadas disseram que assistem à televisão principalmente para se informar, um número significativo. Desse modo, o noticiário televisivo permanece desempenhando um papel importante na divulgação de notícias. Na programação televisiva, como já apontado pela PBM 2015, o telejornal tem local de destaque em função do permanente interesse da população por informação e, segundo Squirra (2004), ele é o programa que gera mais credibilidade às emissoras.

Outro fator de importância são as específicas características dos programas jornalísticos com relação ao resto da programação das emissoras. O telejornal é, pelas características dos assuntos que aborda e veicula, o tipo de programa que mais credibilidade proporciona às emissoras. Credibilidade junto aos anunciantes (cujos espaços para anúncios são geralmente os mais caros) e prestígio junto ao poder político e econômico da nação. Isto por causa da capacidade que tem de falar com os mais diversos tipos e classes sociais que, no geral, caracterizam a televisão e o telejornal possui no particular (SQUIRRA (2004, p. 14).

No entanto, os noticiários diários seguem um mesmo padrão, de modo que as notícias fornecidas por diferentes canais se assemelham, o que gera críticas e preocupação por parte de alguns autores. Não houve uma real inovação. “Os noticiários são um formato obsoleto no ambiente atual de informações instantâneas, sob demanda e de plataforma 


\title{
VOZES $_{\text {\&IÁLORO }}^{\mid}$
}

Itajaí, V. 19, n.02, jul-dez 2020

cruzada.” (NOGUERA-VIVO, 2018, apud GARCÍA-AVILÉS, 2020, p. 144). Nesse sentido, García-Avilés (2020) alerta:

Se as redes de televisão não reagirem à diminuição do consumo de notícias nos telejornais, os noticiários em breve serão irrelevantes. A fórmula que há décadas o noticiário utilizou, com base em um resumo dos destaques do dia em edições do meio-dia e noturnas se tornaram obsoletas, porque na era das mídias sociais, há um fluxo contínuo de notícias 24 horas, as pessoas já conhecem as notícias. Portanto, noticiários precisam se reinventar se não quiserem se tornar irrelevantes" (GARCÍA-AVILÉS, 2020, p. 144).

Apesar das questões levantadas e do "formato obsoleto" (NOGUERA-VIVO, 2018, apud GARCÍA-AVILÉS, 2020), um fato que chama atenção no cenário atual de pandemia do coronavírus é que a audiência dos telejornais, especialmente, aumentou.

A Pesquisa Brasileira de Mídia aponta que, se comparada à TV, a confiança em relação às notícias divulgadas na Internet é bem maior.

\begin{abstract}
Mais da metade dos entrevistados que assistem TV confiam sempre ou muitas vezes nas notícias veiculadas por esse meio. [...] Por sua vez, a maioria dos usuários de internet confia poucas vezes ou nunca confia nas notícias de sites, de blogs e de redes sociais (BRASIL, 2016, p. 33).
\end{abstract}

Esse fato será apresentado no tópico seguinte, levando em consideração uma mudança durante a pandemia do novo coronavírus que colocou a população mundial em busca de informações fidedignas e com credibilidade, para pode ser orientar e se adaptar ao novo contexto. Em casa, confinados, muitos brasileiros passam a maior parte do dia diante da Televisão.

\section{A Covid-19 e o resgate de jovens à TV tradicional}

Diante das fake news propagadas por aplicativos e redes sociais digitais, a pandemia do novo coronavírus (covid-19) mostrou a relevância do jornalismo profissional, uma vez que a população passou a buscar por fontes garantidas de informação.

Em pesquisa ${ }^{4}$ realizada pelo instituto Kantar Ibope Media em 15 capitais brasileiras, no período de 23 a 29 de março, 13 das 20 maiores audiências da TV nos últimos cinco anos foram observadas após o início da pandemia. O jornalismo aparece em $2^{\circ}$ lugar no tempo dedicado pelos telespectadores na programação diária, ficando atrás apenas do

\footnotetext{
${ }^{4}$ Dados do Kantar Ibope Media. Disponível em: https://www.kantaribopemedia.com/brasil-e-osegundo-pais-mais-preocupado-com-a-pandemia-de-covid-79/. Acesso em: 26 abr. 2020.
} 


\section{VOZES $_{\text {\&IÁLORO }}^{\mid}$}

Itajaí, V. 19, n.02, jul-dez 2020

reality show. Ademais, de acordo com 79\% dos entrevistados, é o meio mais confiável para obter informações.

Nesse sentido, outro levantamento do Datafolha ${ }^{5}$, realizado entre 18 e 20 de março, com 1.558 pessoas, apontou que os programas jornalísticos da TV, jornais impressos, programas jornalísticos de rádio e sites de notícias são considerados pelos brasileiros como as fontes mais confiáveis na divulgação de notícias sobre a crise.

Nesse contexto, uma pesquisa da MindMiners ${ }^{6}$ aponta que sites de notícias e TV aberta são os maiores disseminadores de informações verdadeiras. Em contrapartida, os conteúdos que vêm do WhatsApp e Facebook são os menos confiáveis para 58\% e 50\% dos entrevistados, respetivamente. No levantamento, $44 \%$ dos pesquisados afirmam que as notícias disponíveis nas redes sociais são "pouco ou nada" confiável ${ }^{7}$.

Ademais, a revista Veja publicou ${ }^{8}$ matéria informando que a Globo registrou um aumento significativo de jovens na audiência do Jornal Nacional. No mês de março, com o avanço da pandemia de coronavírus no Brasil, a audiência do JN registrou 54,4 milhões de pessoas, em média, por noite, um crescimento de $28 \%$. Neste público, segundo a revista, o aumento mais expressivo está entre jovens de 12 a 24 anos (crescimento de $40 \%$ ), o que aponta que essa faixa etária também está buscando informação em fonte confiável ${ }^{9}$.

No levantamento realizado pelo Kantar Ibope Media, o Consumer Thermometer $\# 7^{10}$, que verificou os impactos da Covid-19 no consumo, mídia e marcas, identificou, no período de 13 a 19 de abril, um aumento médio de $36 \%$ da audiência de TV, por indivíduos acompanhados, se comparado ao período de 02 a 08 de março de 2020.

De acordo com a pesquisa, a audiência de TV aumentou no mundo inteiro no período da quarentena. No Brasil, o tempo de consumo cresceu $19 \%$ em relação ao mesmo período de 2019.

\footnotetext{
${ }^{5}$ Dados do Kantar Ibope Media. Disponível em: https://oglobo.globo.com//brasil/jornais-tvs-saoos-mais-confiaveis-na-hora-de-informar-sobre-coronavirus-aponta-datafolha-24322778. Acesso em: 26 abr. 2020.

${ }^{6}$ Relatório do MindMiners. Disponível em: https://docs.google.com/presentation/d/e/2PACX-1vRPVjPQeUp tZsqMZr6nylp-

2OBTkvJ4RdApJ4UFif8jx3oMm24TXEqEheziP|JhINvDOgcZ6mNruXXd/pub?start=true\&loop=fals e \&delayms=60000\&slide=id.g718888cd4c_O_O. Acesso em: 26 abr. 2020.

${ }^{7}$ Dados do site UOL. Disponível em: https://economia.uol.com.br/noticias/redacao/2020/03/23/coronaviruscrescem-audiencia-e-relevancia-de-noticias.htm. Acesso em: 26 abr. 2020.

${ }^{8}$ Dados do site Veja. Disponível em: https://veja.abril.com.br/blog/radar/globo-comemora-audiencia-jovemno-jornal-nacionall. Acesso em: 26 abr. 2020.

${ }^{9}$ Dados do site Veja. Disponível em: https://veja.abril.com.br/blog/radar/globo-comemora-audiencia-jovemno-jornal-nacionall. Acesso em: 26 abr. 2020.

${ }^{10}$ Relatório do Kantar. Disponível em: https://br.kantar.com/covid-19/. Acesso em: 16 jun. 2020.
} 


\section{VOZES \\ ¿DIÁl OCO}

Itajaí, V. 19, n.02, jul-dez 2020

O levantamento também aponta que o consumo de mídia das gerações mais jovens - Millennials e Centennials ${ }^{11}$ - se acentuou significativamente durante à pandemia. "TV e canais digitais têm atenção dividida e amplificada entre eles, como fonte de entretenimento e informação", informa a pesquisa (KANTAR, 2020). Os jovens declararam ter aumentado o consumo de quase todos os meios e esse crescimento é consideravelmente maior que o das outras faixas etárias.

Já no levantamento seguinte realizado pelo Kantar Ibope Media, o Consumer Thermometer $\# 8^{12}$, de 15 de maio de 2020, 45\% das menções nas redes sociais estavam relacionadas com humor e positividade - memes e piadas; e apenas $5 \%$ se referiam à atualização de notícias, o que corrobora que as informações relacionadas à pandemia disponíveis nas redes sociais não são consideradas por usuários como confiáveis.

Diante destes dados é possível apontar que os telespectadores se reaproximaram da TV e dos noticiários televisivos, inclusive, a juventude. Conforme pesquisas, os programas jornalísticos são as fontes mais confiável para obter informações sobre a pandemia do Coronavírus, enquanto redes sociais digitais são apontadas como as menos confiáveis.

\section{Considerações Finais}

Com este estudo exploratório, que levou em consideração o momento em que está em curso no mundo a pandemia do novo coronavírus, onde a televisão tradicional $\mathrm{e}$, consequentemente, o telejornalismo encontravam-se em crise devido às novas formas de comunicação e à mudança da lógica da comunicação de massa, para uma comunicação interativa, considera-se estar em curso uma alteração do cenário midiático. $\mathrm{O}$ telejornalismo reassume a sua importância, credibilidade e confiança junto ao telespectador jovem, que estava se distanciando deste tipo de mídia e formato, conforme apontavam as pesquisas ao longo dos anos.

Desta forma, a pesquisa identificou novas práticas sociais relativas ao telejornalismo tradicional, que voltou a assumir o seu papel social de mediador, no momento de uma crise de saúde pública, onde o fenômeno das fake news presta um desserviço à sociedade, provocando dúvida, confusão, desinformação e perplexidade.

Os jovens, considerados nesta pesquisa, como as pessoas de 15 a 29 anos de idade, passaram a se interessar pelas notícias devido ao cenário de isolamento social imposto pela pandemia do novo coronavírus, como forma de obter infromações confiáveis.

11 Em geral, se assume que os centennials, também conhecidos como geração Z, são os nascidos a partir de 1996. Os millennials (geração Y) vêm imediatamente antes, mais ou menos a partir de 1982.

12 Relatório do Kantar. Disponível em: https://br.kantar.com/covid-19/. Acesso em: 16 jun. 2020. 


\section{VOZES $_{\text {\&IÁLORO }}^{\mid}$}

Itajaí, V. 19, n.02, jul-dez 2020

A juventude brasileira, de maneira geral, fez um movimento de volta à tela do telejornalismo, em meio à pandemia, visando garantir a obtenção de informação de qualidade, produzida por profissional especializado. Só não se pode ter certeza de que este cenário de reaproximação do telejornalismo com a juventude se manterá depois da quarentena. Isso poderá ser acompanhado e observado em novas pesquisas.

Considerou-se também que, no contexto do novo coronavírus, além do jovem, a população em geral vem buscando o telejornal como fonte primordial de informação, em uma prática social de reaproximação, valorização e ressignificação com a mídia tradicional.

\section{Referências}

BRASIL. Constituição (1988). Constituição [da] República Federativa do Brasil. Promulgada em 05 de outubro de 1988. Senado Federal, Brasília, DF, 05 out. 1988. Disponível em: http://www.senado.gov.br/legislacao/const/con1988/CON1988_05.10.1988/CON1988.pd f. Acesso em: 09 jun. 2020.

BRASIL. Presidência da República. Pesquisa Nacional sobre Perfil e Opinião dos Jovens Brasileiros. Brasília, 09 novembro de 2013. Disponível em: http://www.crianca.mppr.mp.br/arquivos/File/publi/estatisticas/agenda_juventude brasil_vs_jan2014.pdf. Acesso em: 09 jun. 2020.

BRASIL. Presidência da República. Secretaria de Comunicação Social. Pesquisa Brasileira de Mídia 2016: hábitos de consumo de mídia pela população brasileira. Brasília: Secom, 2016. Disponível em: http://www.secom.gov.br/atuacao/pesquisa/lista de-pesquisas-quantitativas-e-qualitativas-de-contratos-atuais/pesquisa-brasileira-de-mi diapbm-2016.pdf/view. Acesso em: 15 fev. 2020.

BRASIL. Relatório Nacional. Pesquisa sobre juventudes no Brasil. IBASE/Instituto Pólis. 2008.2 Disponível: https://ibase.br/userimages/Brasil_ultimarev.pdf. Acesso em: 09 jun. 2020.

BONIN, Robson. Globo comemora audiência jovem no Jornal Nacional. Veja [online], [S. 1.], 03 abr. 2020. Disponível em: https://veja.abril.com.br/blog/radar/globocomemora-audiencia-jovem-no-jornal-nacio nal/. Acesso em: 26 abr. 2020.

CANNITO, Newton Guimarães. A televisão na era digital: interatividade, convergência e novos modelos de negócio. São Paulo: Summus, 2010. 
FECHINE, Yvana. TV Social: contribuição para a delimitação do conceito. Contracampo, Niterói, v. 36, n. 1, p. 84-98, abr./jul. 2017.

FRANÇA, Vera. A televisão porosa - traços e tendências. In: FREIRE FILHO, João (Org.). A TV em transição: tendências de programação no Brasil e no mundo. Porto Alegre: Sulina, 2009.

GARCÍA-AVILES, José A. Reinventing Television News: Innovative Formats in a Social Media Environment [online]. 2020. Disponível em: https://www.researchgate.net/publication/338379504_Reinventing_Television_News_I nnovative_Formats_in_a_Social_Media_Environment. Acesso em: 20 maio 2020.

GARCÍA-CANCLINI, Néstor. Leitor, espectadores e internautas. São Paulo: Iluminuras, 2008.

INSTITUTO BRASILEIRO DE GEOGRAFIA E ESTATÍSTICA (IBGE). Censo Demográfico Brasileiro de 2010. Rio de Janeiro: IBGE, 2012. Disponível em: <http://www.ibge.gov.br/home/

estatistica/populacao/censo2010/default.shtm>. Acesso em: 22 mar. 2020.

JENKINS, Henry. Cultura da convergência. 2. ed. São Paulo: Aleph, 2009.

JORNAIS E TVS são os mais confiáveis na hora de informar sobre coronavírus, aponta Datafolha. O Globo [online], [S. 1.], 2020. Disponível em: https://oglobo.globo.com/brasil/jornais-tvs-sao-os-mais-confiaveis-na-hora-deinformar-sobre-coronavirus-aponta-datafolha-24322778. Acesso em: 26 abr. 2020.

JUNQUEIRA, Juliana. Telejornalismo e violência: o processo de construção e desconstrução da cidadania em notícias sobre criminalidade. 2013. 231f. Dissertação (Mestrado em Comunicação) - Universidade Federal de Goiás, Goiânia, 2013.

KANTAR IBOPE MEDIA. Brasil é o segundo país mais preocupado com a pandemia de Covid-19. Disponível em: https://www.kantaribopemedia.com/brasil-e-osegundo-pais-mais-preocupado-com-a-pandemia-de-covid-19/. Acesso em: 26 abr. 2020.

KANTAR IBOPE MEDIA. Consumer Thermometer \#7. [S. 1.], 2020. Disponível em: https://br.kantar.com/covid-19/. Acesso em: 16 jun. 2020. 


\section{VOZES $_{\text {\&DÁLOGO }}^{\mid}$}

Itajaí, V. 19, n.02, jul-dez 2020

KANTAR IBOPE MEDIA. Consumer Thermometer \#8. [S. 1.], 2020. Disponível em: https://br.kantar.com/covid-19/. Acesso em: 16 jun. 2020.

MARTINS, Renata Echeverria. As Representações Sociais do Nordeste no Jornal Nacional. 2017. 207f. Tese (Doutorado em Comunicação) - Universidade Federal de Pernambuco, Recife, 2017.

MATA, Jhonatan Alves Pereira. O Amador no Audiovisual: a incorporação de conteúdos gerados por cidadãos comuns às produções jornalísticas da televisão brasileira. 2017. 201f. Tese (Doutorado em Comunicação) - Universidade Federal do Rio de Janeiro, Rio de Janeiro, 2017.

MÉDOLA, Ana Silvia Lopes Davi; TEIXEIRA, Lauro Henrique de Paiva. Aspectos da TV Digital Interativa: Como pode ficar a nova televisão do ponto de vista do usuário [S. l.], 2008. Disponível: https://www3.faac.unesp.br/anaiscomunicacao/textos/35.pdf. Acesso em: 14 de jun. de 2020.

MENESES, Beatriz. Monitoramento COVID-19 - Terceira Onda. Blog Mindminers, [S. l.], $30 \quad$ mar. 2020. Disponível em: https://mindminers.com/blog/monitoramento-covid-19-terceira-onda/. Acesso em: 26 abr. 2020 .

PEZZOTTI, Renato. Coronavírus: crescem audiência e relevância de notícias. Portal UOL, São Paulo 23 mar. 2020. Disponível em: https://economia.uol.com.br/noticias/redacao/2020/03/23/coronavirus-crescem-audienciae-relevancia-de-noticias.htm. Acesso em: 26 abr. 2020.

SANTOS, Leandro Olegário dos. A reconfiguração da notícia: um estudo sobre o impacto do ciberacontecimento na rotina produtiva no telejornalismo. 2018. 221f. Tese (Doutorado em Comunicação) - Pontífica Universidade Católica do Rio Grande do Sul, Porto Alegre, 2018.

SQUIRRA, Sebastião Carlos de Morais. Aprender telejornalismo: produção e técnica. São Paulo: Brasiliense, 2004.

VALERO-PASTOR, José Maria. El informativo transmedia: Lecciones de otros formatos audiovisuales. [S. 1.], 2019. Disponível em: https://www.researchgate.net/ publication/333080019_El_informativo_transmedia_Lecciones_de_otros_formatos audiovisuales. Acesso em: 25 maio 2020. 